\title{
CRÍTICA E POLÍTICA EM MÁRIO DE ANDRADE
}

\section{Bianca Ribeiro Manfrini}

RESUMO: Este artigo procura relacionar os dois aspectos centrais da obra de Mário de Andrade: o crítico e o criativo e estético. Por meio dessa relação, procuramos demonstrar como a política é, na verdade, a força capaz de unificar esses dois aspectos da obra do escritor, guiada em sua totalidade por um esforço não apenas de entendimento da cultura brasileira, mas de democratização da mesma, presente na totalidade de sua obra porém com ênfases diferentes, relacionadas por sua vez ao momento histórico e social do país em conexão com a reflexão estética do autor.

Palavras-chave: Mário de Andrade; Modernismo; Crítica; Política.

ABSTRACT: This article aims to relate the two main aspects of Mário de Andrade's work: the critical and the aesthetical and creative. Through this relation, we try to show how politics is, in fact, the force able to unify these two aspects of the writer's work, guided in its totality by an effort not only of understanding the Brazilian culture, but of democratizing it, in an effort that is present throughout all his work, but with different aspects related to the historic and social moments of Brazil, always connected to the aesthetic reflection of the writer.

KEYWORDS: Mário de Andrade; Modernism; Criticism; Politics. 
No ensaio "Por um historicismo renovado: reflexo e reflexão em história literária", de 2002, Alfredo Bosi traça um panorama da crítica literária brasileira, compreendendo seus momentos mais importantes desde o Instituto Histórico e Geográfico, da época de Pedro II, até as figuras de Antonio Candido e Otto Maria Carpeaux, passando por José Veríssimo, Sílvio Romero, Araripe Jr., Alceu Amoroso Lima, Afrânio Coutinho e Mário de Andrade. Neste último, Bosi vê um crítico tomado pela "obsessão de definir o caráter nacional, o modo de ser brasileiro, a nossa psicologia coletiva, o nosso inconsciente", $\mathrm{e}$ detecta em Mário uma oscilação entre formalismo e historicismo, ou seja, um conflito, na obra do escritor, entre o critério estético e o critério nacional. Ora, sabemos que a questão da nacionalidade sempre foi importante para a nossa crítica, de José Veríssimo e Sílvio Romero a Antonio Candido e Alfredo Bosi, passando por essa figura-chave de criador e crítico que é Mário de Andrade. Nosso artigo tem como objetivo demonstrar a ambivalência entre crítica e estética na obra de Mário, deslindando suas implicações políticas, ligadas ao momento histórico em que se constitui sua obra, pois, ainda citando Bosi: "Esta percepção da incompletude e de um certo grau de indeterminação do 'caráter nacional' é uma constante do pensamento de Mário [...] da mesma generosa matriz romântica, de que derivou boa parte da crítica moderna, fluíram na sua obra a vertente histórico-nacional e a vertente existencial e universalizante". ${ }^{2}$ Em outro ensaio - "Mário de Andrade crítico do modernismo", 3 Bosi comenta a conferência de 1942, "O movimento modernista", na qual Mário faz um balanço da trajetória de sua geração. Para o crítico, essa fala de Mário tem o peso de uma contradição apontada e não resolvida - a da defasagem entre a práxis artística e a práxis social, uma tensão não resolvida que exprime o que está vivo no movimento. É essa tensão que será o assunto central de nossa discussão.

Assim, a obra de Mário de Andrade pode ser dividida em duas partes - a artística e literária e a ensaística e teórica. A partir dessa divisão iremos comentar as relações entre estética e política presentes no projeto intelectual do escritor. Direcionado a uma democratização da arte que passava por questões como a conciliação entre a arte erudita e a popular, esse projeto redunda em fracasso quando Mário tenta colocá-lo em prática durante seu trabalho como diretor do Departamento de Cultura da cidade de São Paulo,

\footnotetext{
1 Bosi, Alfredo. Literatura e resistência. São Paulo: Companhia das Letras, 2002, p. 23.

2 Idem, p. 25.

3 Idem. Céu, inferno. São Paulo: Editora 34, 2010.
} 
criado em 1935 e desmantelado pelo Estado Novo, num episódio que desencadeou uma crise pessoal e artística que marca os últimos anos de vida do autor de Café. Durante esse período, Mário volta-se para uma defesa enfática do comunismo, como pode ser lido no prefácio que escreveu para Dmitri Shostakovich, de Victor Seroff. Do modernismo iconoclasta dos anos 1920, passando pelo nacionalismo e pelas pesquisas folclóricas dos anos 30 até o engajamento radical dos anos 40, há um caminho cuja coerência é pautada por um "antimodernismo" que nos leva a pensar em sua obra mais como reação do que como adesão à arte moderna, numa tentativa de reelaboração crítica de formas importadas que nasce em contato com os obstáculos de uma estrutura social desigual que, juntamente com um governo autoritário, impede qualquer tentativa mais ampla de democratização cultural.

Desse modo, levanta-se a questão de uma modernidade que se articula de maneira específica em nossa literatura, não encontrando paralelo, por exemplo, com o processo social que deu origem às vanguardas europeias, surgidas em meio a um público já formado e familiarizado com a linguagem da arte, mesmo que conservador. Como falar em "público literário" num país que, em 1922, realizava uma revolução artística em meio a uma maioria analfabeta, revolução essa que buscava justamente fazer ver esse problema, através de mudanças na linguagem? É por isso que o nosso modernismo deve ser entendido mais em termos de construção do que de destruição. Construção de uma literatura que se quer "um bem de todos", ${ }^{4}$ fundando o movimento na vida profunda de toda a sociedade, como observa Antonio Candido; uma arte nascida do povo e elaborada pelo artista erudito. Essas são justamente as premissas de Mário de Andrade que, nos anos 1940, em sua conferência “O movimento modernista", revê as conquistas de 22 com uma lucidez que até hoje não é devidamente apreciada no contexto de uma trajetória intelectual marcada politicamente pelo anseio de democratização da arte, mas presente em toda a sua obra, marcada por um desdobramento que revela a impossibilidade de ser somente artista, a necessidade de dedicar-se a outros assuntos para ser um artista completo, num país em formação. Esse desdobramento é tão intenso que divide a sua obra em duas: "a parte messiânica e a parte evasão", ${ }^{5}$ como ele menciona em carta a Prudente de Moraes,

\footnotetext{
4 CANDIDo, Antonio. “A literatura na evolução de uma comunidade”. In: Literatura e sociedade. São Paulo: Publifolha, 2002, p. 150.

5 Andrade, Mário de. Cartas de Mário de Andrade a Prudente de Moraes, Neto. Rio de Janeiro: Nova Fronteira, 1985, pp. 293-294.
} 
Neto. A primeira, “arte-ação", fraca, transitória, inteligente: a que mais o orgulha como homem. A segunda, lírica, inteligente, que lhe agrada como prazer artístico mas sem o mínimo valor crítico, segundo ele. Por diversas vezes, em sua correspondência com Manuel Bandeira, Henriqueta Lisboa, Oneyda Alvarenga, entre outros - Mário menciona o "sacrifício" da parte mais puramente artística de sua obra, quase toda direcionada a problemas de circunstância, a conquistas e inovações estéticas feitas conscientemente para abrir caminho aos que virão. É como se a "arte pura" fosse impossível em nosso contexto, de modo que a "arte-ação" é testemunho da impossibilidade da arte mais individual, ao mesmo tempo que a justifica. Há aí uma noção muito clara de que, num país de cultura própria recente como o nosso, é necessária primeiramente a arte utilitária, de combate, para que depois venha a arte mais "desinteressada" de seu contexto histórico próximo, preocupada com questões universais. É por isso que, em 1928, Mário de Andrade nega ser artista: "todos os meus trabalhos jamais não foram vistos com visão exata porque toda a gente se esforça em ver em mim um artista. Não sou. A minha obra desde Paulicéia desvairada é uma obra interessada, uma obra de ação". ${ }^{6}$ E, em carta a Fernando Sabino, de 1945, ele reafirma a ideia: "Beethoven escreveu A Heroica pra depois escrever a Pastoral"' ' Essa clivagem na obra de Mário de Andrade falaria, de certo modo, de uma obra incapaz de se realizar plenamente somente no plano estético, incapaz de tomar uma forma exata, estável; a parte, digamos, "ensaística" de sua produção (numa separação esquemática, para fins práticos) - na qual se incluem seus estudos e boa parte de sua correspondência - serviria como uma espécie de compensação e explicação a um projeto estético e político de modernidade democrática que fracassou por diversos motivos, entre eles o advento do Estado Novo, devastador para o Departamento de Cultura da cidade de São Paulo, do qual Mário foi o diretor entre 1935 e 38. Enquanto ocupou esse cargo, o autor da Lira paulistana vislumbrou a possibilidade de pôr em prática seus projetos intelectuais, numa empreitada cujo final levou ao radicalismo político que surge em seus escritos e entrevistas dos anos 40. Do entusiasmo modernista à crise da última década de sua vida, podemos sistematizar, adicionando alguns detalhes à divisão proposta por Roberto Schwarz, ${ }^{8}$ três fases em sua trajetória intelectual, excetuando-se a Obra

6 Idem. Ensaio sobre a música brasileira. São Paulo: Martins, 1972, p. 73.

7 Idem. Cartas a um jovem escritor. Rio de Janeiro: Record, 1981, p. 141.

8 Sobre o assunto, ver schwarz, Roberto. "O psicologismo da poética de Mário de Andrade". Rio de Janeiro: Paz e Terra, 1981. 
imatura: os anos 1920 (de 1922 a 1928), nos quais rompe com a estética parnasiana e se posiciona dentro do movimento modernista; os anos 1930 (de 1928, data de publicação do Ensaio sobre a música brasileira, a 1938, ano em que se desliga do Departamento de Cultura), marcados por sua definição e atuação política: o apoio hesitante a São Paulo em 1932, através das colunas do Diário Nacional, a direção de um órgão municipal; e os anos 1940 (de 1938 a 1945), de amadurecimento político, crise pessoal e estética e sofrimento físico, marcados ainda pela continuidade, em outro diapasão, de seu envolvimento com o Estado Novo, agora ligado à figura de Gustavo Capanema, o ministro da Educação e Saúde de Vargas. De maneira bastante complexa, vai se esboçando nesse caminho todo um projeto no qual o conceito aristotélico de política ("o homem é por natureza um animal político"), ${ }^{9}$ amplo, encontra-se associado a um sentimento democrático em relação à arte (num país de tradição democrática pobre) que não pode ser definido simplesmente como aquilo que Daniel Pécaut chama de "populismo intelectual", ${ }^{10}$ ou seja, a política que se disfarça em cultura para tutelar e controlar um povo que supõe "ignorante", cultuando a democracia apenas formalmente, num discurso bem distante da prática. No entanto, ao mesmo tempo que Mário propõe uma aproximação efetiva e igualitária entre o intelectual (no Brasil, um ser de exceção) e as pessoas do povo - "viva de preferência com colonos e gente baixa do que com delegados e médicos. Com a gente baixa você tem muito o que aprender embora não pra bancar o primitivista, é lógico", ${ }_{11}^{11}$ aconselha ele, em 1926, a Drummond -, a "política" no sentido mais estrito seria alvo de desprezo em suas cartas até os anos 1940, nos quais uma virada socializante, associada tanto ao Estado Novo quanto à polarização mundial causada pela guerra, irá alterar sensivelmente o discurso de Mário, que se sente obrigado a tomar partido, posicionando-se contra o fascismo. Não é por acaso que, nesse mesmo momento, amadurece em seu pensamento estético uma noção mais realista de uma arte especificamente brasileira, situada entre a cultura erudita e a popular, criada pelo mulato Pe. Jesuíno do Monte Carmelo, espécie de desenvolvimento de "O Aleijadinho", de 1928.

Se Mário atuou com Oswald de Andrade durante os primeiros anos do modernismo, coube ao último a fama de "escritor político", enquanto o primeiro, cercado de fichas de leitura, estaria às voltas somente com questões estéticas. Mas os clichês não resistem

\footnotetext{
9 ARISTóteles. Política. São Paulo: Martin Claret, 2015, p. 146.

10 PÉCAUT, Daniel. Intelectuais e a política no Brasil: entre o povo e a nação. São Paulo: Ática, 1990.

11 ANDrade, Mário de. A lição do amigo. Rio de Janeiro: Record, 1988, p. 76.
} 
a um olhar mais detido: a política não possui a consistência definidora de todo um projeto intelectual na obra de Oswald; após a conversão à crítica da burguesia operada na passagem de Os condenados a Memórias sentimentais de João Miramar, o autor, nos anos 1940, vai oscilar, inconsistente, tanto em seu posicionamento quanto em sua obra: ora crê na glória de uma nova "era atômica" que surgiria com o fim da Segunda Guerra, como lemos nas conferências de Estética e política, ora se mostra pessimista, como no descosido Marco zero (I e II). Já a obra de Mário é marcada desde o início por um certo posicionamento político que se mantém até o fim de sua vida: desde o "Conto de Natal", de 1914, até o prefácio a Dmitri Shostakovich, de Victor Seroff, acompanhamos um intelectual que não se furta às questões do momento; como observa Telê Ancona Lopes, Mário "não estreia, como a maioria dos poetas de seu tempo, com o lirismo amoroso, mas com a tentativa de compreender sua época".13 O judeu de "Conto de Natal" que vaga pela São Paulo da belle époque e fustiga os dançarinos estrangeiros e hedonistas numa boate chique é um Cristo antimoderno. O projeto estético de Mário é desde o início um projeto político, e não há separação entre esses dois elementos pois, engajado numa visão crítica da modernidade em geral, ele evolui até apresentar um ponto de vista que problematiza a existência dessa mesma modernidade no Brasil. Macunaíma não é apenas a crítica à ausência de caráter nacional, mas vislumbra a ausência de caráter de uma arte que se furta à tradição, cada vez mais individualizada e distante do público, que vem se sobrepor aos nossos problemas já existentes; a rapsódia, canto de um povo, seria a resposta ao isolamento da arte moderna; no entanto, o romance padece, dado o seu caráter experimental e sua absorção de procedimentos vanguardistas, dos mesmos paradoxos e se arrisca às mesmas restrições de público dos romances modernos de sua época. $\mathrm{O}$ esforço de enraizar Macunaíma em chão brasileiro entrega justamente aquilo que nele é universalmente moderno: a ausência de raízes de um ser cuja busca redunda em fracasso.

A elaboração do pensamento estético de Mário de Andrade - para ele, a palavra Arte abrigava dois grandes ramos: as artes aplicadas, utilitárias (culinária, bordados, cerâmica etc.) e as Belas Artes - passa por uma consciência profunda da desigualdade brasileira, pois aqui o estágio de civilização necessário para a normalização social das Belas Artes não existia. Nascida num momento em que o povo brasileiro começa a se configurar como potencialidade democrática, principalmente no contexto das metrópo-

12 Presente em Primeiro andar, parte de sua Obra imatura.

13 LOPEz, Telê Porto Ancona. Mário de Andrade: ramais e caminho. São Paulo: Duas Cidades, 1972, p. 29. 
les nascentes, sua obra incorpora o impasse entre o popular e o erudito, ainda ausente, por exemplo, em Machado de Assis, em cuja literatura não se constitui como tensão formadora central. Machado dá conta, no entanto, de uma questão que, se não está resolvida para Mário, pelo menos já vai bastante adiantada: a da formalização de nossa situação histórica e a importação da forma. ${ }^{14}$ Para Mário, Machado teria se isolado num pessimismo frio para criar um estilo irretocável. Ele não podia ver que, ao inovar a forma romanesca por dentro, o autor das Memórias póstumas equacionava de maneira crítica o conteúdo histórico de seu tempo, assim como Mário que, ao encarar o problema da distância entre o povo e a arte erudita, criou uma profusão de gêneros (rapsódia, idílio, ópera etc.) que mesmo assim não foram suficientes para seu anseio de superação artística - sintoma esse de uma síntese nunca alcançada. Se em relação a Machado temos sempre a impressão de uma obra fechada, perfeita, bem-acabada, em relação a Mário não é estranho o sentimento de obra incompleta, grandiosa porém malograda, expresso por ele mesmo em sua correspondência, permeada pelo leitmotiv: "faço obra de circunstância". Isso ocorre porque ele vivenciou de forma intensa um impasse que marca mas ultrapassa a sua obra, sobrevivendo a ela: o da possibilidade de uma arte para todos num país autoritário ou de frágil democracia. Como saída desse impasse, Mário via na música, arte de efeito direto e caráter coletivo, uma maneira de maior difusão artística; no Ensaio de 1928 ele diz: "a música popular brasileira é a mais completa, mais totalmente nacional, mais forte criação de nossa raça até agora". ${ }^{15}$ Parece ser desse pensamento que nasce, nos anos 1940 (após o reconhecimento das falhas do modernismo e do fracasso de Macunaíma, “'obra-prima' que falhou"), ${ }^{16}$ a ópera Café, com texto politicamente engajado e música de Francisco Mignone; essa obra nunca chegou a ser encenada. Sendo a ópera o gênero de música erudita mais popular na época (tanto que era desaconselhada pelos cartazes à vista dos ouvintes da Discoteca Municipal, escritos por Mário), a escolha dessa forma, unida ao teatro, que era, para Mário, a forma de arte mais direta e impositiva, acrescentada de um texto que oscila entre o grandioso e o panfletário, buscava não somente um contato com um público mais vasto, mas a sua comoção total. Para Antonio Candido,

14 Esses comentários baseiam-se na leitura de Ao vencedor as batatas: forma literária e processo social nos inícios do romance brasileiro e Um mestre na periferia do capitalismo: Machado de Assis, ensaios de Roberto Schwarz sobre Machado de Assis.

15 ANDrade, Mário de. Ensaio sobre a música brasileira. São Paulo: Martins, 1972, p. 24.

16 Idem. Cartas a um jovem escritor, p. 30. 
o texto, impressionante na época, perdeu força com o passar do tempo, tornando-se forçado, "como se Mário quisesse cumprir uma tarefa política sem encontrar o tom certo". ${ }^{17}$ À dificuldade de dar forma ao tema da tensão social e à crise pessoal dos anos 1940 também corresponde ao romance inacabado Quatro pessoas, bem como à forma em romance de Café, nunca publicada.

A pouca ênfase dada ao Mário de Andrade do fim dos anos 1930 e dos anos 1940 parece demonstrar uma certa má vontade de levar em conta as autocríticas do escritor, que colocam o dedo em feridas ainda abertas. Afinal, para além das conquistas de 22, deve-se também levar em conta a abstenção política de uma geração que não "marchou com as multidões", como ele aconselhou no fim de sua conferência de 1942, além da presença de lugares-comuns modernistas que ainda encontram lugar na literatura contemporânea, dando a impressão de que o modernismo permanece em boa parte insuperado. A coragem do ajuste de contas de Mário com o modernismo não encontrou ecos nem entre os jovens da época, nem na crítica e na geração que o precederam, daí a tensão ainda presente apontada por Bosi e mencionada no início de nosso ensaio.

Para Mário, o grande perigo que rondava a arte erudita brasileira era a absorção acrítica dos modernismos estrangeiros, como se bastasse ao artista dar vazão a suas idiossincrasias individuais, numa fôrma já pronta. Não: a forma deve comunicar, e por isso deve ser feita com o conhecimento profundo da técnica, esta a parte coletivizadora por excelência da obra de arte. As conquistas técnicas são, conscientemente ou não, sempre conquistas coletivas, históricas, como bem demonstra Eric Auerbach na sequência de ensaios que compõem seu Mimesis. De modo que não basta apenas mimetizar as vanguardas estrangeiras; o artista deve, a partir da riqueza da cultura popular, plasmar uma técnica pessoal que leve em conta as conquistas da tradição que o antecedeu. É a lição de Machado de Assis, só que em chave democrática, pois Mário não estava dentro dos limites do Brasil imperial e escravocrata. Por isso, também, a insistência nos dois momentos da arte: a criação e a reflexão, que falam em negativo de uma arte brasileira que, mesmo em seus estratos eruditos, tende a ser somente espontânea. E ofazer crítico do artista é importante justamente em decorrência do contexto do qual brota sua arte: ela deve ser uma forma de provocação à superação de um trauma que se encontra no seio mesmo da sociedade da qual se originou. Junto a essa consciência local forte, está uma visada crítica da inflação da técnica na arte moderna que, ao contrário do que

17 Souza, Gilda de Mello e. “A lembrança que guardo de Mário”. Revista do IEB, 36. São Paulo, 1994, p. 17. 
notou Roberto Schwarz, ${ }^{18}$ não surge totalmente positiva no pensamento de Mário, apresentando matizes que podem nos levar a supor que sua obra é mais uma reação do que uma absorção da arte moderna, constituindo assim um "antimodernismo" dialético e sui generis, formulado na seguinte passagem de uma carta a Oneyda Alvarenga, em 1940: "o conhecimento técnico pode inflar, pode se desenvolver abusivamente, pode tomar o lugar da expressão, substituindo-se a esta e sendo a determinante exclusiva da criação. E esta inflação e substituição é a grande causa que o Sérgio [Milliet] tanto procura no divórcio entre arte e público, nos nossos dias". ${ }^{19}$ Nas entrelinhas, está o projeto de criação de uma arte brasileira, de maneira análoga à que Machado fez com o romance. Em meio a tudo isso, não podemos esquecer que Mário é o nosso primeiro "intelectual nacional", correspondendo-se com escritores de todo o Brasil e realizando, através da troca epistolar, aquilo a que Marcos de Moraes dá o nome de "projeto pedagógico", ${ }^{20}$ numa empreitada de sedução intelectual que atua na obra de Drummond, Fernando Sabino e Villa-Lobos, entre outros, e que possui certamente teor político. Além disso, o caráter "ordinário" das cartas, nas quais boa parte de seu pensamento se desenvolve, está justamente ligado à sua estética democrática: as cartas contêm um estilo de reflexão cotidiano e participante, no sentido de que interferem diretamente na vida dos interlocutores.

A essa figura capaz de articular dialógica e coletivamente seu projeto intelectual, corresponde, coincidentemente, um projeto político de centralização nacional que tem lugar nos anos 1930 e se desenvolve num relacionamento tenso entre intelectuais e Estado que, apesar das críticas dos primeiros (em uma de suas cartas a Henriqueta Lisboa, Mário coloca "até o meu prezado amigo Capanema" no grupo dos "nazistizantes" que ele gostaria de mandar pelos ares), ${ }^{21}$ nunca se rompe, pois se baseia sobretudo em relações mais pessoais do que propriamente políticas (numa situação análoga à descrita por Daniel Pécaut, em que a "culltura" substitui a política para encobrir o autoritarismo). Assim, é necessário ver os pontos de confluência e distanciamento entre o complexo panorama político da época e o projeto do escritor, evitando os dois extremos: aquele

18 Para o crítico, a noção de técnica em Mário de Andrade permanece diurna, sem a dimensão irracionalista que pode possuir. Ver o ensaio já citado de A sereia e o desconfiado.

19 Andrade, Mário de. Cartas: Mário de Andrade, Oneyda Alvarenga. São Paulo: Duas Cidades, 1983, p. 291.

20 MORAes, Marcos Antonio de. Orgulho de jamais aconselhar. São Paulo: Edusp, 2007.

21 Andrade, Mário de. Querida Henriqueta: cartas de Mário de Andrade a Henriqueta Lisboa. Rio de Janeiro: José Olympio, 1990, p. 80. 
que ergue demais o autor acima de seu meio, idealizando-o, e aquele que o mergulha demais em seu contexto (útil para o estudo de panoramas sociais vastos, como faz Sergio Miceli) ignorando suas especificidades.

Estética e política se encontram num ponto comum: o de remediar e sugerir a superação das imperfeições da vida humana, como está postulado em O Banquete, espécie de tentativa de fusão entre as duas vertentes da obra de Mário - é um tratado estético encenado em forma de diálogo, com personagens fictícios -, no qual ele sistematiza seu pensamento sobre arte. Nessa obra publicada postumamente (ela está entre os escritos dos anos 1940 que foram deixados inacabados e, ironia do destino, fala do caráter inacabado que toda arte de combate deve possuir), a arte erudita surge como construção social, nascida da sociedade de classes. Surge, nas entrelinhas, a noção do caráter pouco representativo que essa mesma arte pode possuir no Brasil, dada a importação das formas e o individualismo reinante entre os artistas brasileiros. $\mathrm{O}$ conceito de primitivo, largamente explanado no Curso de filosofia e história da arte de $1938 \mathrm{em}$ toda a sua complexidade, é reformulado n'O Banquete, aplicado ao contexto nacional e agora claramente político: nossa arte deve retornar ao primitivo no sentido de participar socialmente, integrada na coletividade, fugindo ao estiolamento da arte moderna europeia. Se a sociedade cultua a morte (num pensamento que pode lembrar Adorno), talvez a fusão entre o erudito e o popular possa significar uma saída para o impasse dessa mesma arte. Se é uma tortura criar no vago, sem uma longa tradição antecedente e sem garantias de permanência póstuma, é também uma dádiva poder criar em contato com uma arte viva nas multidões que ainda (na primeira metade do século $\mathrm{xx}$ ) cantam e dançam o folclore. É de se notar, também, uma contradição que não se resolve nessa obra: por vezes encontramos uma grande idealização do artista, onipotente em sua "liberdade de criação", a qual convive com observações cortantes sobre o caráter de construção ideológica que confere a aura de prestígio às artes. Embora essas contradições se articulem bem na forma do diálogo, que abre espaço para proposições que não precisam necessariamente ser resolvidas, a obra fala de uma idealização que permeou toda uma geração, pois sem esta não seria possível criar e ao mesmo tempo pertencer ao Estado Novo. Está além da capacidade de autocrítica de Mário - que não era pouca - reconhecer plenamente a condição social do artista, notando que não somente os donos da vida mas também os próprios artistas são culpados pela reificação da arte, afastando-a da coletividade. Se bem que, nas cartas a Fernando Sabino, essa consciência surja de forma contundente: ou o artista serve ao poder, ou está contra ele. E isso ele faz através da obra de arte, num pensamento que exclui a ação pessoal, dado o fracasso 
do Departamento de Cultura e a permanência de sua ligação com o Estado Novo, mas que é também um ganho crítico, ao notar a política entranhada na própria estrutura das obras.

Não é somente na noção da autonomia, da objetividade da obra de arte, que fala por si, que o pensamento de Mário se aproxima do de Theodor Adorno. Coincidência ou não, o inacabado Banquete tem como último prato uma salada americana que mais parece uma alegoria da cultura de massa: visual, hipnótica, sem cheiro e sem história, ${ }^{22}$ cabe a ela o tom premonitório final do diálogo, encenando o encontro da falta de caráter macunaímica da maioria dos ali presentes (em contraste com a lucidez e a seriedade de Janjão, cuja expulsão do festim estava planejada para a última parte) com a resplendente cultura de massa, a salada que é o prato cheio da alienação. Esse final encontra sua contrapartida dialética no prefácio a Shostakovich: ali Mário apresenta uma visão bastante equilibrada do compositor russo, vendo na indústria cultural um espaço que permite a conciliação entre o erudito e o popular, dois elementos que Shostakovich utiliza largamente em suas obras. Se em "Atualidade de Chopin" estava presente a identificação entre o projeto de Mário e o compositor romântico, autor de uma obra nacional e popular mas ao mesmo tempo complexa e sem concessões, no estudo sobre Shostakovich fica subentendido que o ponto de encontro entre o escritor e o músico é o "antimodernismo" do segundo, situado entre o burguês e o popular, bem como o caráter transitório de sua obra. Talvez nesse prefácio que antecede em um mês sua morte esteja a crítica mais forte da arte moderna que Mário realizou publicamente em sua vida, em conjunto com uma defesa enfática do comunismo e com um tom de descrença na democracia que se esquece da ausência de comunismo estabelecido no Brasil, como na Rússia, e também da inexistência de uma democracia nacional para se descrer dela. Mário não notava, ou pelo menos não formulava claramente, o fato de que seus estudos de folclore se desenvolviam num Estado autoritário, assim como deu pouca importância às perseguições pelo governo soviético sofridas por Shostakovich. Nos anos 1940, ele não possui a firmeza da visão crítica que Patrícia Galvão, por exemplo, já formulava sobre a União Soviética, dado seu afastamento dos meios comunistas.

Ora, então qual o motivo dessa adesão fervorosa e tardia a uma causa que até então atraía sua simpatia e guiava, de certa forma, seu projeto (no qual, como demons-

22 Andrade, Mário de. O Banquete. São Paulo: Duas Cidades, 1989, p. 159. 
trou Telê Ancona Lopes, ${ }^{23}$ há um forte fundo socializante), mas que nunca chegou a vir à tona de forma tão decisiva? Nos parece que a polarização mundial causada pela Segunda Guerra é insuficiente para responder a essa questão. Essa adesão é antes o ponto final do desenvolvimento de um projeto malogrado de democratização da arte para o qual a única saída, segundo Mário naquele momento, era a revolução social, o engajamento radical. O projeto dos anos 1920 e 30 encontra sua culminância na criação do Departamento, para o qual Mário se entrega totalmente, deixando em segundo plano o trabalho intelectual - entrega essa que, para alguns de seus amigos, como Paulo Duarte, foi a principal causa da tristeza que antecedeu os anos de sua morte, ${ }^{24}$ gerada pelo fim do Departamento, estrangulado pela administração Prestes Maia, revelando que o projeto do "intelectual nacional" dos anos 1930, apesar das afinidades que levaram Antonio Candido a achar "curioso, este caso de uma vanguarda político-cultural à sombra de uma situação oligárquica que a aceitou e a apoiou", ${ }^{25}$ não era exatamente o mesmo projeto de Estado de Getúlio Vargas. Assim, não foi possível estabelecer, no âmbito ainda (aparentemente) democrático (o Departamento foi fundado em 1935), um projeto sólido de democratização cultural, afinal ele mesmo não estava imune a traços autoritários de "tutelagem" do povo, e que sobrevivesse às intempéries de uma ditadura que só aguardava o momento certo para se manifestar. Fechado esse caminho, Mário se direciona para uma adesão forte ao comunismo, que, no entanto, não o impede de trabalhar sob a direção de Capanema, no Rio de Janeiro, e promove uma virada em sua obra: é a insatisfação manifesta em "O movimento modernista", da qual também nasce Café. Da preocupação com o nacional, predominante nos anos 1920, há uma gradual conscientização da coletividade (numa espécie de retorno amadurecido ao engajamento de Há uma gota de sangue em cada poema), elaborada nos anos 1940, nos quais a questão da participação e da convicção política do artística assume uma clareza inédita.

23 LOPEz, Telê Porto Ancona. Mário de Andrade: ramais e caminho, op. cit.

24 Paulo Duarte, envolvido ativamente em prol da Revolução Constitucionalista de 32, foi quem convenceu Mário a trabalhar no Departamento. Em Mário de Andrade por ele mesmo, acompanhamos a correspondência entre os dois, na qual Mário desabafa as amarguras e angústias que sucederam ao seu desligamento do Departamento. Em uma dessas cartas, ele faz menção ao seu "irrespirável, bolorento espírito democrático", que o faz acreditar na possibilidade da razão dos outros contra as suas razões. Ver: DuARTe, Paulo. Mário de Andrade por ele mesmo. São Paulo: Hucitec, 1985, p. 159.

25 Prefácio a DuARTe, Paulo. Mário de Andrade por ele mesmo, op. cit., p. xvi. 
Do nacional e popular, passando pela ação governamental e desaguando em forte simpatia pela coletividade internacional comunista, consequência do fracasso de nossa "democracia" autoritária, o trajeto de Mário é exemplar e representativo em vários sentidos. Na virada drástica dos anos 1930 para os anos 40, ela se desenvolve sem perder a coerência. Não fica esquecido o desejo de uma arte ao mesmo tempo erudita e popular, esboçada nos anos 1920, mas os meios para alcançá-la tornam-se outros. No fracasso de uma prática democrática de difusão cultural, os caminhos percorridos por Mário falam diretamente ao nosso tempo, no qual apesar de democracia efetiva a arte erudita permanece para poucos, a arte popular agoniza e a arte "popularesca" (para usar uma definição na qual Mário não punha nenhum preconceito) impera entre as camadas pobres, a maioria da população. Por vezes, tem-se a impressão de parada no tempo: algumas iniciativas de Mário para a cidade de São Paulo, como a Discoteca Pública, sobrevivem mas não se expandem; a maioria morreu, e a biblioteca que leva seu nome sobrevive num semiabandono triste. Sua agonia, aquele sentimento difuso de abatimento que ele relatava nas cartas após o desligamento do Departamento, não terminou. Sua obra modernista traz em seu bojo a crítica da modernidade; como lemos n'O Banquete, a arte pela arte era para ele a fuga do problema moral do artista moderno. Seu projeto estético amadurece em um projeto político capaz ainda de nos provocar e levantar questões sobre a situação da literatura brasileira no século xx. Não é por acaso que duas das maiores obras literárias dessa época, Grande sertão: veredas e A hora da estrela, derivam da consciência reflexiva do artista erudito em seu contato com o contexto brasileiro, decantada numa forma que, como condição de sua modernidade, teve que passar necessariamente por esse problema central de nossa sociedade, que Mário de Andrade soube enfrentar de maneira precursora, corajosa e complexa. Ele calculou mal sua permanência: se pode ter sido "transitório" no que legou de conquistas estéticas para seus sucessores, que as continuaram e desenvolveram, permaneceu ao tocar no nervo de nosso processo de modernização - a exclusão.

Bianca Ribeiro Manfrini é Doutora em Letras pela Universidade de São Paulo 